Supplement of Earth Syst. Dynam., 9, 1141-1153, 2018

https://doi.org/10.5194/esd-9-1141-2018-supplement

(c) Author(s) 2018. This work is distributed under

the Creative Commons Attribution 4.0 License.

(c) (1)

Supplement of

\title{
Pipes to Earth's subsurface: the role of atmospheric conditions in control- ling air transport through boreholes and shafts
}

Elad Levintal et al.

Correspondence to: Noam Weisbrod (weisbrod@bgu.ac.il)

The copyright of individual parts of the supplement might differ from the CC BY 4.0 License. 


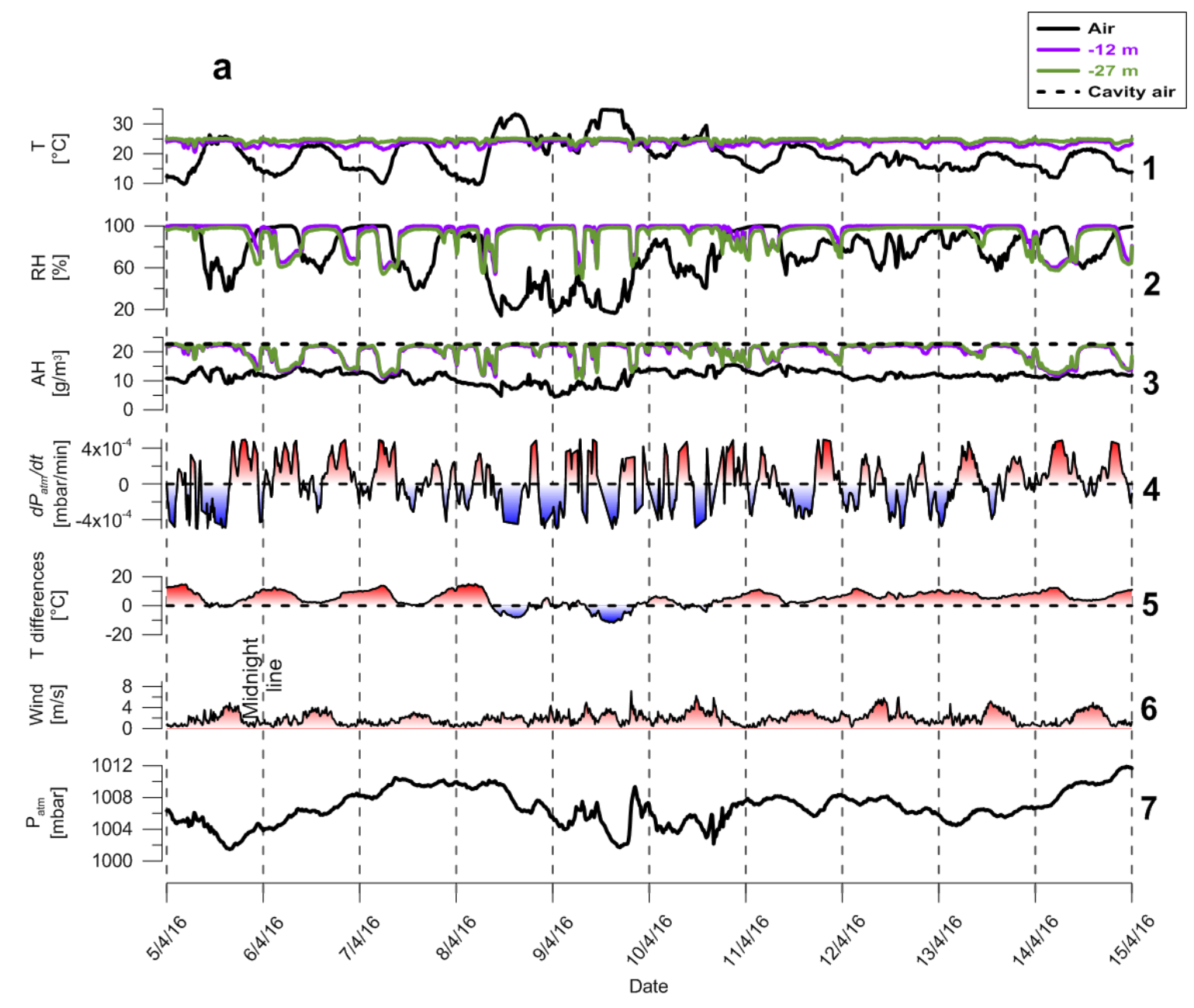




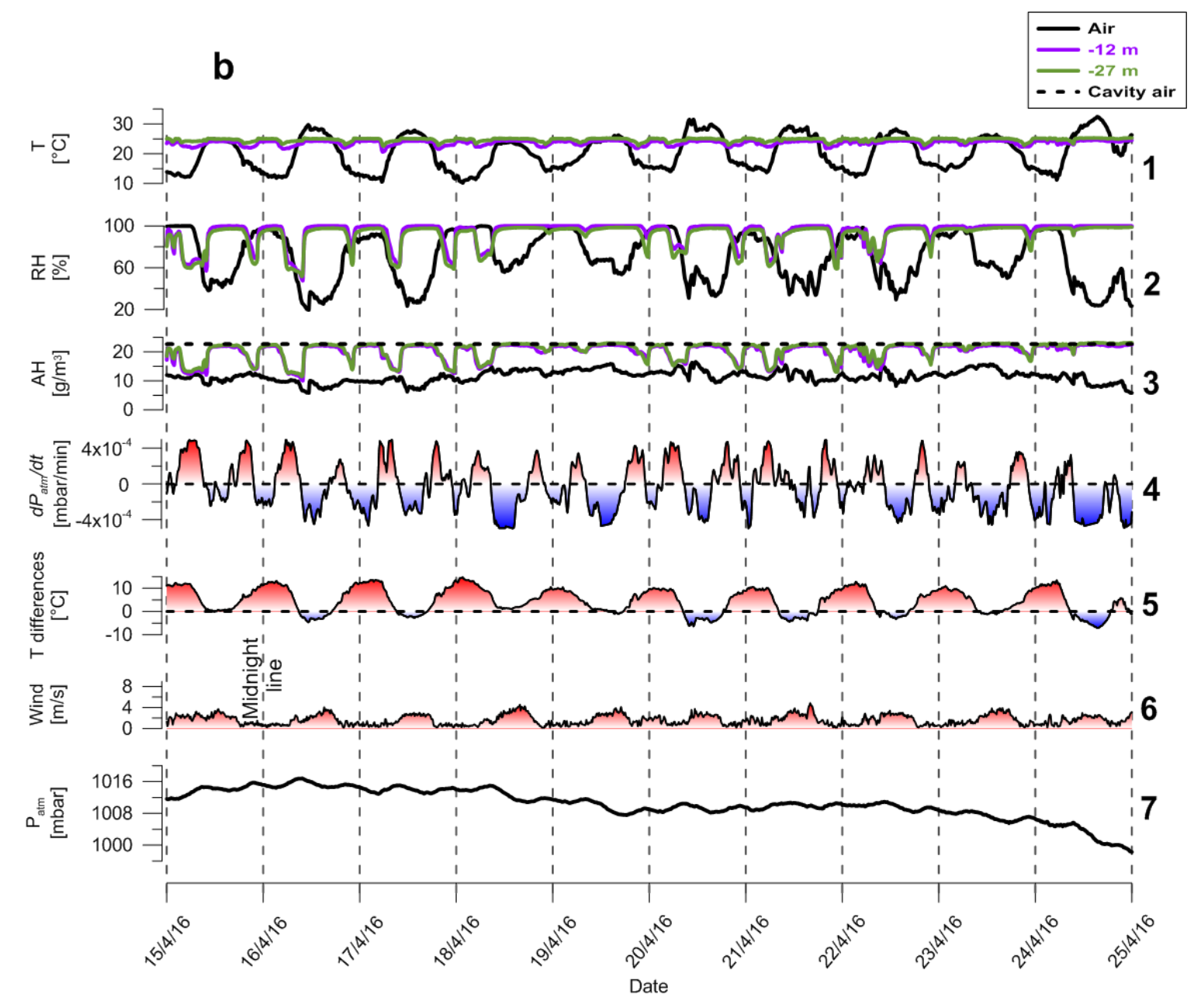




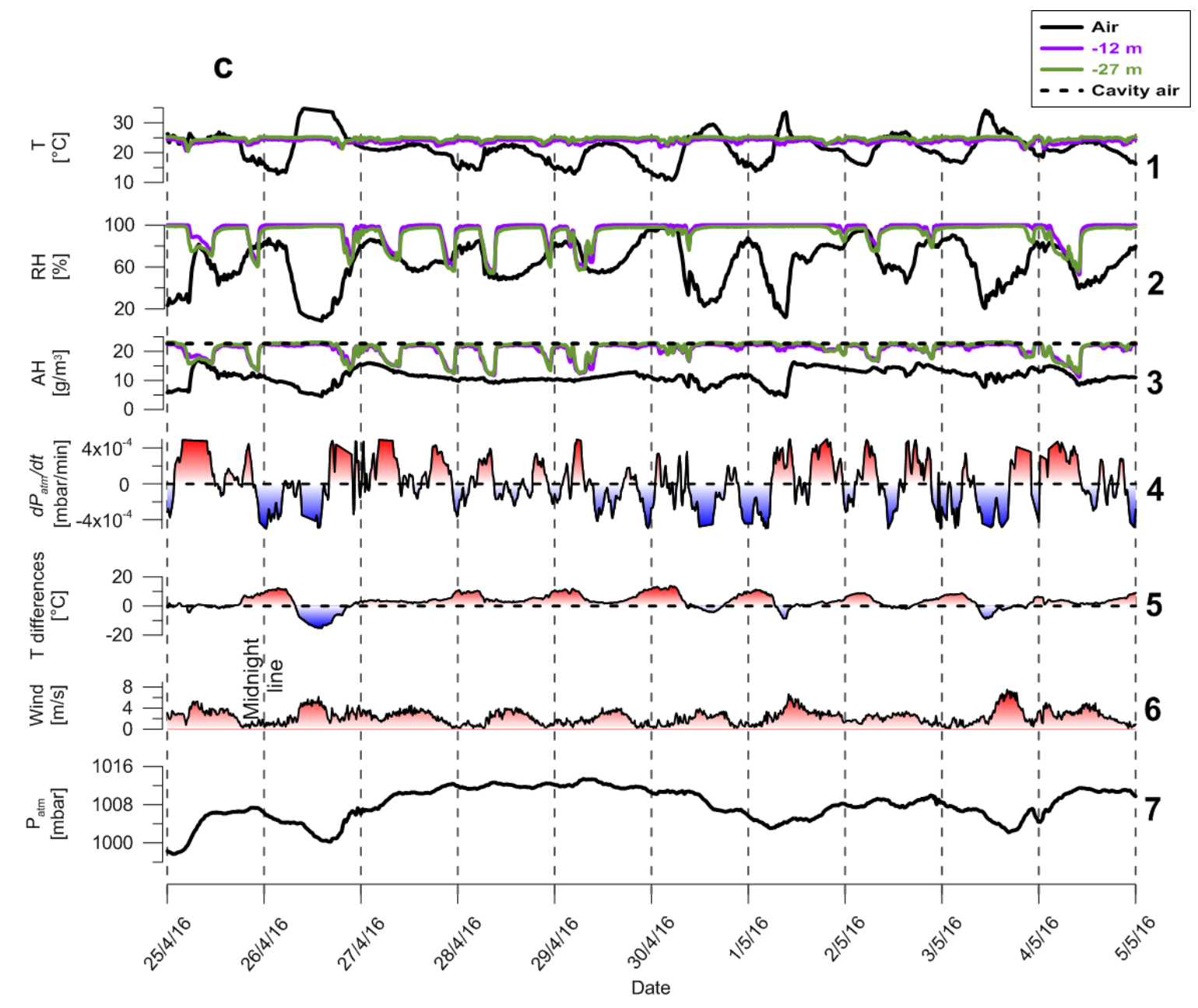




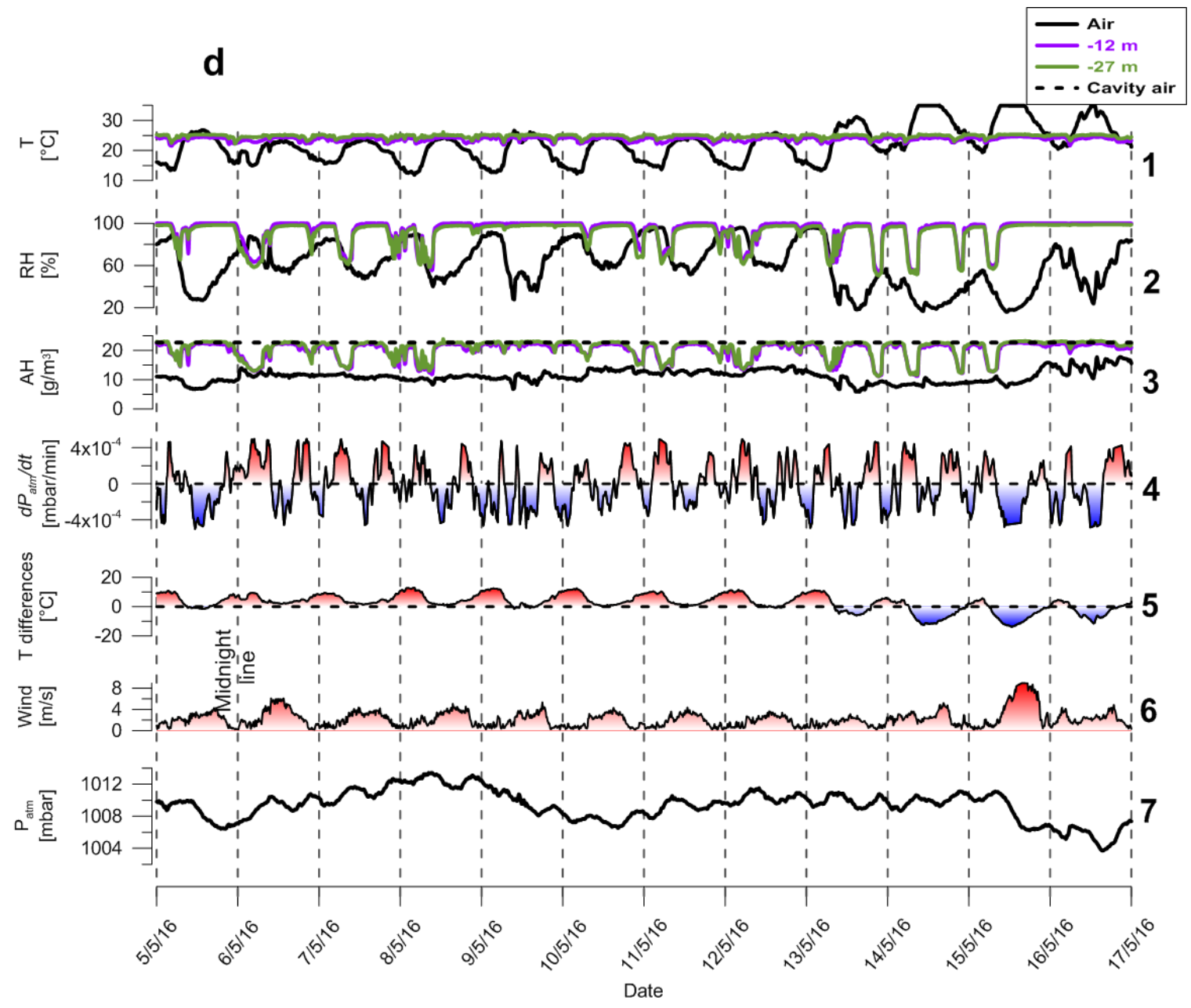

Figure. S1. Time series results from the full 42-day shaft observations. Absolute humidity (AH) values were calculated using Eq. (1). The lower boundary (black dashed line in 3) was approximated as constant with $\mathbf{T}=$ $24.7^{\circ} \mathrm{C}$ and $\mathrm{RH}=100 \%$. $\mathrm{T}$ differences values (5) represent the temperature differences between the sensor at 12 $\mathrm{m}$ depth and the sensor above ground. 


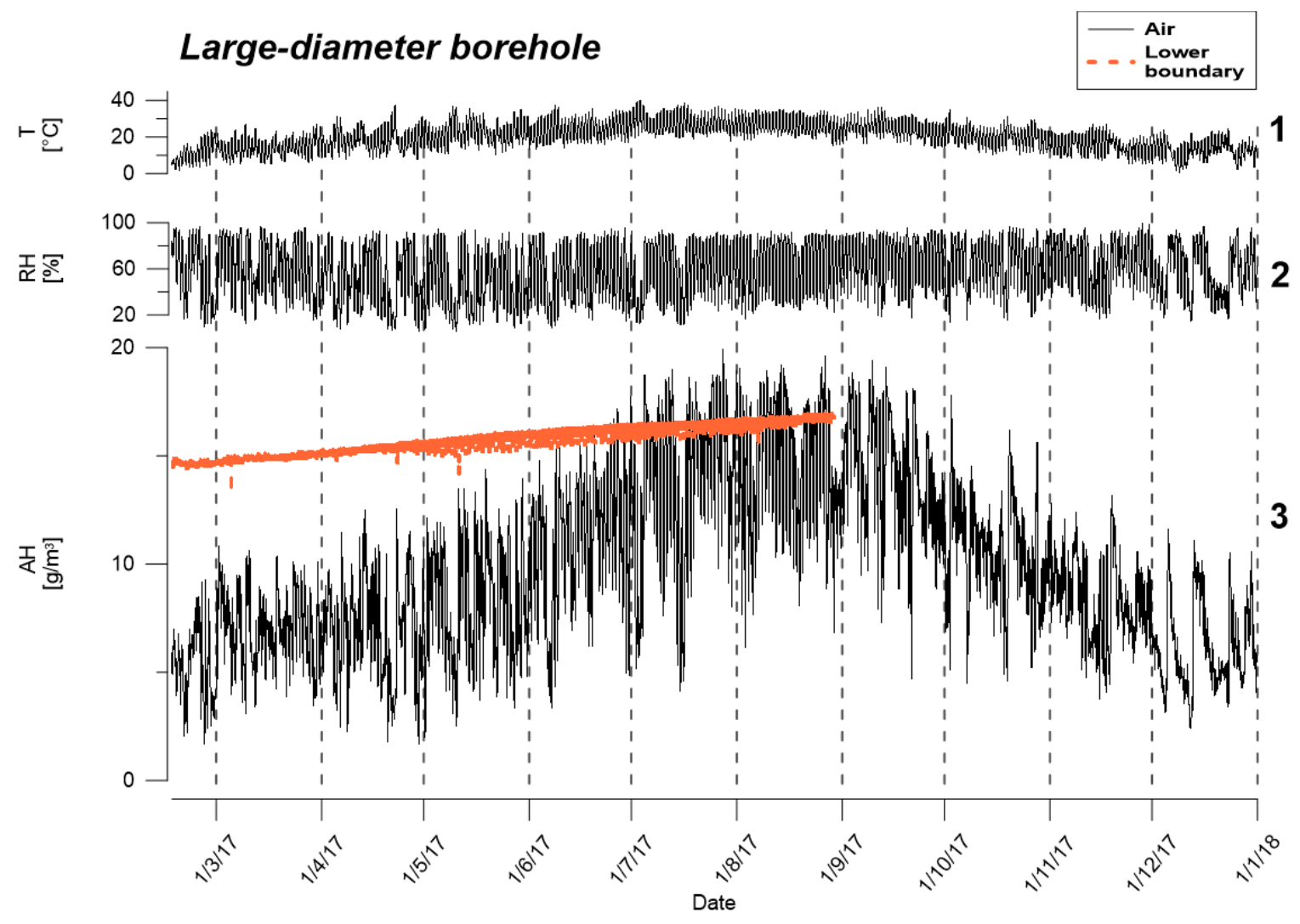

Figure. S2. Seasonal time series results of absolute humidity (AH) from the large-diameter borehole. From midFebruary to the end of June, the use of $\mathrm{AH}$ as a proxy for airflow direction was valid due to the differences of AH between the borehole's lower boundary and the atmosphere. Between July and August (summer season), the AH differences were no longer constant (see also Fig. S3), and therefore we can conclude that AH was no longer a suitable proxy for the identification of airflow directions within the borehole. AH data for the borehole are missing from September until December; however, it is reasonable to assume that during that period, the $\mathrm{AH}$ as 10 a proxy was also relevant because $\mathrm{AH}$ within the borehole was stable. 


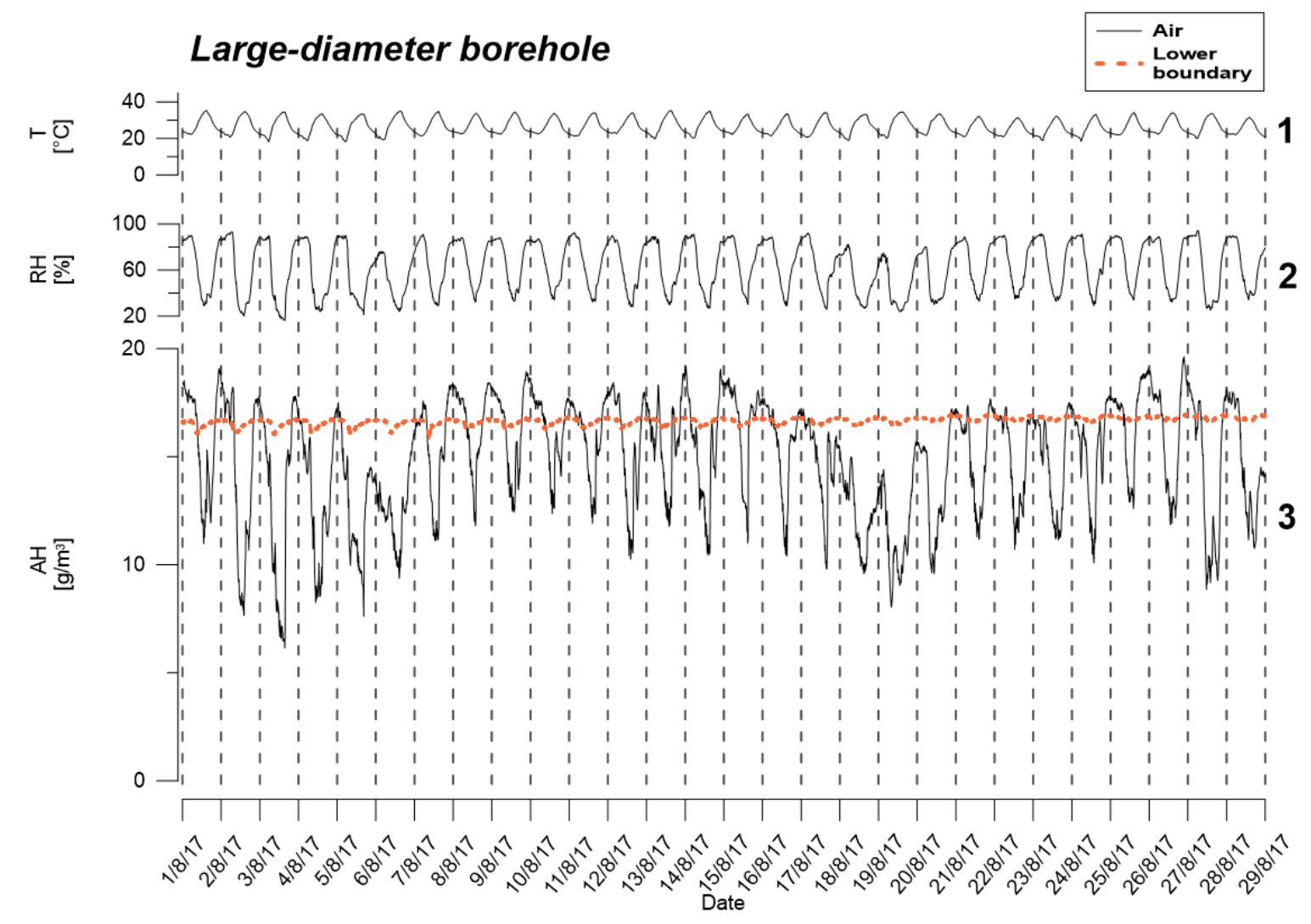

Figure. S3. August time series results of absolute humidity $(\mathrm{AH})$ from the large-diameter borehole. 